УДК 621.181.2

DOI https://doi.org/10.32838/2663-5941/2019.3-2/25

\title{
Данилян А.Г.
}

Дунайский институт

Национального университета «Одесская морская академия»

Тирон-Воробъёва Н.Б.

Дунайский институт

Национального университета «Одесская морская академия»

\section{Романовская O.P.}

Дунайский институт

Национального университета «Одесская морская академия»

\section{Маслов И.3.}

Дунайский институт

Национального университета «Одесская морская академия»

\section{СОВЕРШЕНСТВОВАНИЕ СИСТЕМЫ ОБЕЗЗАРАЖИВАНИЯ И ОЧИСТКИ БАЛЛАСТНЫХ ВОД}

В статье изложена проблематика «скопления-переселения» чужеродных инвазий с постоянным «переносом» балластной воды на морских судах; также внимание акиентируется на основных требованиях нововведённой конвенции ИМО (англ. International Maritime Organization, IMO) (в частности, более «ужесточённое» требование D-2). По заданной конвенщии (ссылаясь на основныле правила и придержсиваясь основных требований) авторами - сотрудниками Дунайского института НУ «ОМА» (2. Измаил) приведена доработанная усовершенствованная схема-конщепиия по разработке установки для обеззараживания и очистки балластных вод морских судов. Заданная концепиия основывается на нанотехнологических принципах усовершенствования очистного сооружения балластных вод. Надлежсащим преимуществом 8 предложенной установке являются необходимые «ключи-подходыр», с одной стороны, мочного химического реагента, с другой же - высокотехнологичного конструктивного решения (более усовершенствованного, включающего принципы электрогидроудара), позволяющего избежсать глубокого «заражения» балластных вод инвазивными чужеродными видами, в частности, индикаторными микробами.

Ключевые слова: балластные воды, угроза морских судов, инвазии, забортная вода, система обеззаражсивания и очистки балластных вод, электрогидроудар.

Состояние (постановка) проблемы в общем виде и её связь с важными научными или практическими заданиями. В ранее опубликованных научных трудах авторов по данной тематике была предусмотрена конкретная цель - создание системы обеззараживания и очистки балластных вод на уровне современных требований D-2. Для этого были изучены новейшие установки обеззараживания и очистки балластных вод ведущих мировых производителей: Alfa Laval, Hyde Guardian, Ray Clean ${ }^{\mathrm{TM}}$, Elite Marine Ballast, Water Treatment System Corp и др. Многие из них далеки от уровня предъявляемых требований ИМО 71-й Конференции (МЕРС 71/17) Комитета по защите морской среды.

Правило-требование D-2 определяет следующие нормативы качества балластных вод, которые должны содержать:
1) менее 10 жизнеспособных организмов размером 50 мкм или более в наименьшем измерении на один кубический метр;

2) менее 10 жизнеспособных организмов размером от 10 до 50 мкм в наименьшем измерении на один $\mathrm{cm}^{3}$.

Индикаторные микробы, используемые для целей стандартов охраны здоровья человека, в следующих концентрациях:

1) токсигенный холерный вибрион (серогруппы O1 и О139) - менее 1 колониеобразующей единицы (КОЕ) на $100 \mathrm{~cm}^{3}$ или менее $1 \mathrm{KOE} \mathrm{на}$ 1 г (сырого веса) образцов зоопланктона;

2) кишечная палочка - менее $250 \mathrm{KOE}$ на $100 \mathrm{~cm}^{3}$;

3) кишечные энтерококки - менее $100 \mathrm{KOE}$ на $100 \mathrm{~cm}^{3}[1]$. 
Анализ последних исследований и публикаций. Появление болезнетворных опасных штаммов в балластных водах стало достаточно частым явлением, если учесть, что сброс сточных вод в отдельных странах Африки, Индокитая производится без должной санитарной обработки. По результатам проводимых исследований в китайских портах на протяжении ряда лет выявлены болезнетворные штаммы кишечной палочки E. coli, в три и более раз превышающиепредельный уровень [2]. Частыми становятся случаи по обнаружению и выявлению холерного вибриона в прибрежных водах острова Гаити; гепатит C, A часто обнаруживается в моллюсках, населяющих побережье Индии.

Наш Черноморский бассейн становится плацдармом переселений инвазий из других водных ресурсов планеты. Обнаружены новые виды пришельцев: многощетинкового червя - полихета Streblospio sp. (впервые был обнаружен в Новороссийском порту в 2001 г., в устье реки Цемес с численностью 980 экз./м²). Наблюдается большое количество средиземноморской копеподы-вселенца - циклопоидной Oithona davisae. Все эти инвазии появились в Чёрном море в связи с постоянным «перемещением» балластных вод судов. На фоне приближающейся техногенной катастрофы Чёрного моря в Украине Кабинет Министров отменил контроль изолированных балластных вод в портах (Постановление от 27 марта 2019 г.) с целью сниже- ния коррупционной составляющей при контроле судов экологическими службами портов. На первый взгляд данное постановление отвечает международным нормам контроля балластных вод, которые в 2015 году были отменены во всем цивилизованном мире. К сожалению, Украина не пошла по пути электронного контроля, оставив открытым вопрос защиты от чужеродных инвазий своих территориальных вод. В настоящее время цивилизованный мировой флот проводит перевооружение судов в соответствии с требованиями D-2. Последние требования ИМО по сбросу балластных вод будут контролироваться специальным оборудованием с оповещением экологических служб портов в режиме онлайн (рис. 1) [3].

\section{Формирование целей статьи.}

Целью статьи является обоснование ранее предложенной схемы-системы управления обеззараживанием и очисткой балластных вод с соответствующим дополнением - применением электрогидроудара - более эффективного принципа уничтожения чужеродных инвазий.

Изложение основного материала исследования с полным обоснованием достигнутых научных результатов. Ранее разработанная сотрудниками Дунайского института Национального университета «Одесская морская академия» (ДИ НУ «ОМА», г. Измаил) принципиальная схема по обеззараживанию и очистке балластных вод в настоящее время доработана и усовершенствована

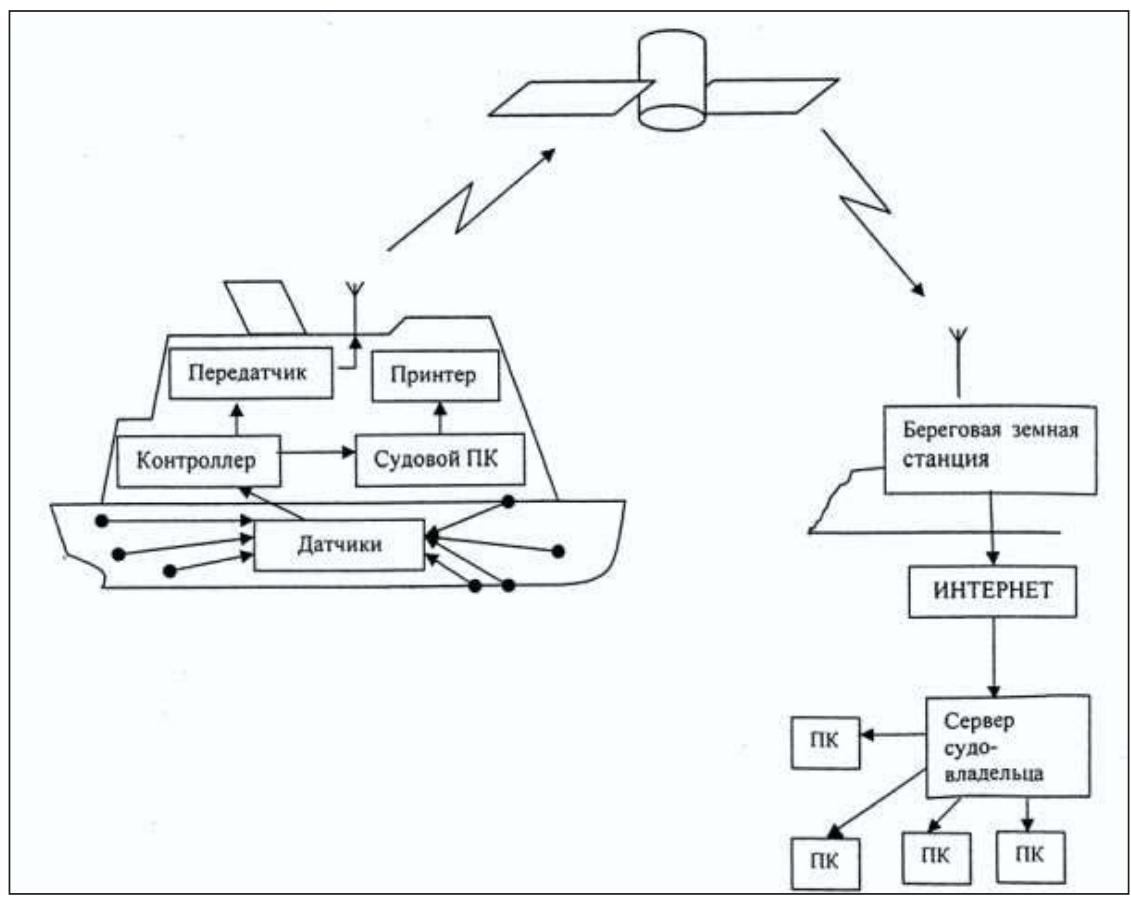

Рис. 1. Блок-схема системы мониторинга процесса замены балластных вод 
с учётом повышенных требований D-2 (рис. 2 Принципиальная схема очистки балластных вод, разработанная авторами статьи).

По мнению авторов статьи, удалось подойти к $100 \%$ обеззараживанию и очистке балластных вод благодаря интегрированиюв схему очистки системы обеззараживания эффекта электрогидравлического удара. Данный метод впервые используется в установках подобного типа.

Обеззараживание сточных вод электрогидроударом зарекомендовало себя на протяжении длительного периода использования как эффективный и достаточно дешёвый метод уничтожения бактериальных колоний и патогенных штаммов.

Перенос данного метода в сферу деятельности Мирового морского флота сулит большие финансовые выгоды, значительно повышая уровень уничтожения инвазий, обеззараживая и очищая балластные воды.

На рис. 3. показана схема создания электрогидравлического эффекта (ЭГЭ), включающая источник питания с конденсатором в качестве накопителя электроэнергии. Напряжение на конденсаторе повышается до значения, при котором происходит самопроизвольный пробой воздушного формирующего промежутка, в этот момент вся энергия, накопленная в конденсаторе, мгновенно поступает на рабочий промежуток в жидкости, где и выделяется в виде короткого электрического импульса большой мощности. В дальнейшем сам процесс проходит при заданной ёмкости и напряжении, повторяясь с частотой, зависящей от мощности питающего трансформатора.
Опытным путём были установлены основные параметры ёмкости и напряжения различных рабочих режимов, которые увеличивают силу пробоя либо её снижают. Были установлены следующие режимы:

- жёсткий: $\mathrm{U}>50$ кВ; $\mathrm{C}<0,1$ мкФ;

- средний: 20 кВ $<\mathrm{U}<50$ кВ; 0,1 мкФ< $<<1,0$ мкФ;

- мягкий: $\mathrm{U}<20$ кВ; $\mathrm{C}>1,0$ мкФ.

Диаметр искры (стример) пропорционален мощности импульса, сам стример имеет достаточно плотную структуру, вокруг которого наблюдается высвобождение тепловой энергии с высокой ионизацией жидкости с появлением повышенной кавитации. Давление на оболочке стримера достигает десятков тыс. бар и более, которое резко снижается от оболочки к периферии в ёмкости с водой.

ЭГЭ обладает мощным воздействием на жидкость, сравнимый с радиационным химическим эффектом высокой степени ионизации.

В ранних опытах, поставленных ещё в 50-х годах, показаны хорошие результаты гибели бактерий под действием электрогидравлических ударов. Доказано, что под воздействием электрогидроударов в жидкости появляется мощный источник ультразвукового эффекта. В диапазоне 10-40 кГц звуковое давление составляет $2 * 10^{6}$ Па, что и является основным фактором интенсивной гибели микроорганизмов.

Под действием ультрафиолетового и рентгеновского излучения плазмы канала стримера с выделением атомарного кислорода происходит полное сжигание всего органического, находящегося в воде. Варьируя показателями создания

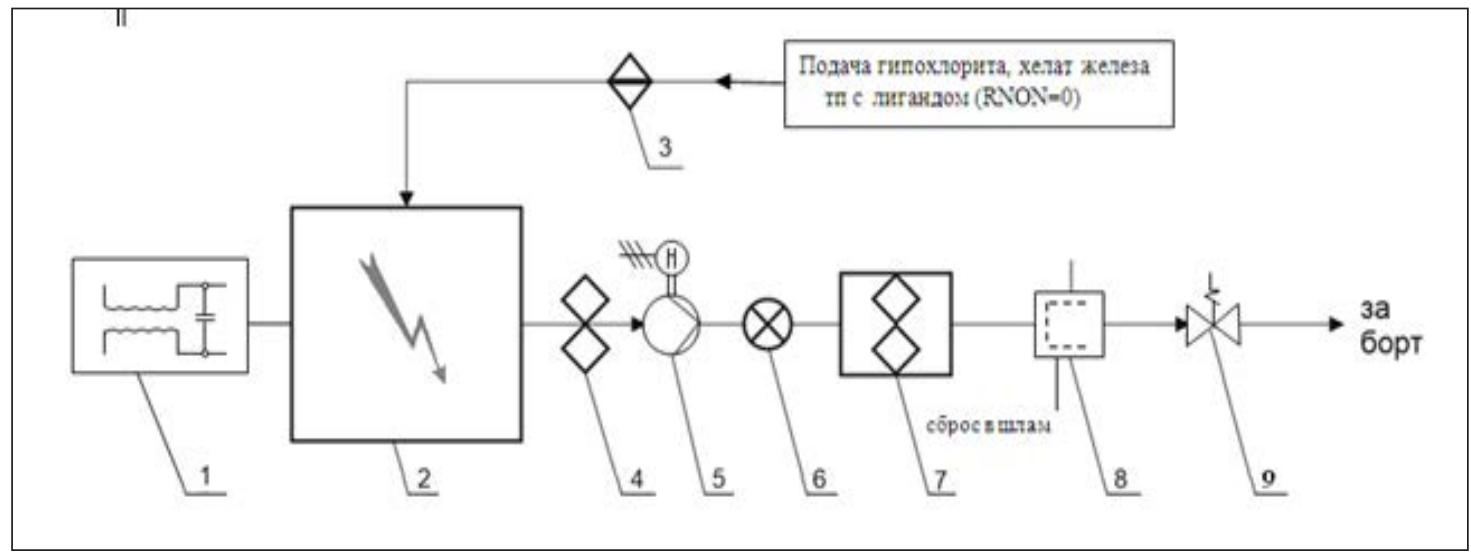

Рис. 2. Принципиальная схема очистки балластных вод, разработанная авторами статьи ДИ НУ «ОМА», г. Измаил: 1 - высокочастотный блок электрогидроудара, 2 - балластный танк, 3 - дозатор реагентов, 4 - фильтр грубой очистки, 5 - балластный насос, 6 - регулятор подачи воды, 7 - камера УФ, 8 - саморазгружающийся фильтр тонкой очистки, 9 - быстрозапорный клапан 


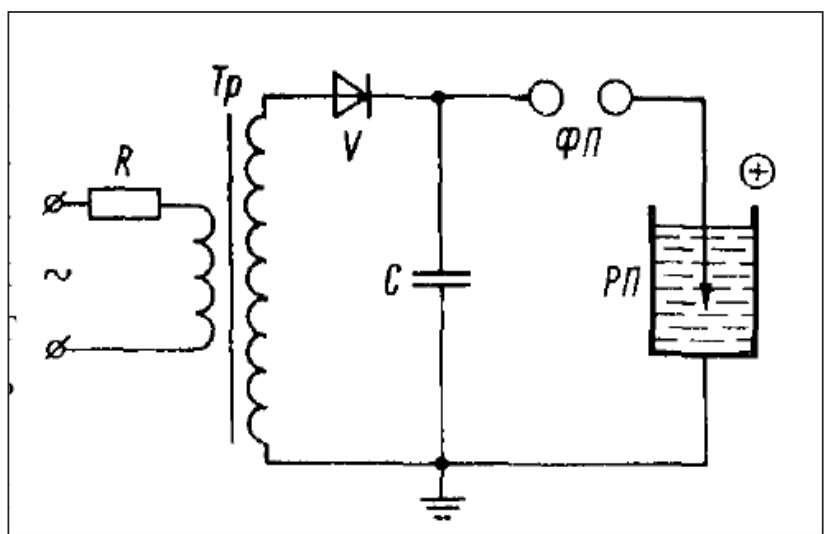

Рис. 3. Электрическая схема для воспроизведения ЭГЭ с одним формирующим промежутком: $\mathbf{R}$ - зарядное сопротивление, $\mathbf{T P}$-трансформатор, V - выпрямитель, ФП - формирующий искровой промежуток, РП - рабочий искровой промежуток в жидкости, С - конденсатор

электрогидравлического удара и изучив особенности инвазий, болезнетворных штаммов, находящихся в балластной воде, можно разрушать любую клеточную структуру живых организмов [4].

Схема вновь доработанной установки принципиально отличается от многих других установок ведущих мировых фирм. В ней заложены два основных элемента, ранее никогда не использованные для обеззараживания и очистки балластных вод. Это система ЭГЭ и система саморазгружающегося фильтра тонкой очистки с применением вращающихся фильтровальных дисков из наноуглеродных трубок, выращенных искусственным путём.

Выводы. Предлагаемая установка для использования её в Мировом морском флоте имеет неоспоримые преимущества: саморазгружающийся фильтр с наноуглеродными вставками, который позволяет делать отсев твёрдых элементов и микроорганизмов в изолированных балластных водах до 10 микрон с низким сопротивлением проходящей воды; применение нового реагента хелата железа для обеззараживания и уничтожения (очистки) живых организмов в балластной воде, который прошёл успешные испытания по уничтожению вредных моллюсков в растениеводстве, что даёт полную уверенность его использования в изолированном судовом балласте; интегрирование системы ЭГЭ для обработки балластных вод является самым действенным элементом предлагаемой установки. Энергозатраты установки составляют 0,2-0,3 кВт на $1 \mathrm{~m}^{3}$, что вполне приемлемо для использования даже на самых больших океанских судах, где производительность откачки балласта доходит до $\mathrm{Q}=6$ тыс. $\mathrm{M}^{3} /$ час.

\section{Список литературы:}

1. Доклад комитета по защите морской среды на его семьдесят первой сессии. ИМО, 18 августа 2017 г., Лондон. С. 20.

2. Звягинцев А.Ю., Селифонова Ж.П. Исследование балластных вод коммерческих судов в морских портах России. Российский Журнал Биологических Инвазий. 2008. № 2, С. 10.

3. Proceedings of the VIII International Scientific and Practical Conference. International Trends in Science and Technology. Vol. 2, Desember 25, 2018, Warsaw, Poland. Данилян А.Г., Быковец Н.П., Тирон-Воробьева Н.Б. Новый подход в локализации инвазивных пришельцев в балластных водах морских судов. С. 10-15.

4. Юткин Л.Ю. Электрогидравлический эффект и его применение в промышленности. Ленинград : «Машиностроение», 1986. С. 246.

\section{УДОСКОНАЛЕННЯ СИСТЕМИ ЗНЕЗАРАЖЕННЯ ТА ОЧИСТКИ БАЛАСТНИХ ВОД}

У статті викладено проблематику «скупчення-переселення» чужорідних інвазій з постійним «перенесенням» баластної води на морських судах; також увага акцентується на основні вимоги відповідно до нововведеної конвениї IMO (англ. International Maritime Organization, IMO) (зокрема, більш «жорстка» вимога D-2). За заданою конвенщією (посилаючись на основні правила та дотримуючись основних вимог) авторами - співробітниками Дунайського інституту НУ «ОМА» (м. Ізмаӥл) приведено допращьовану вдосконалену схему-концепиію з розробки установки для знезараження й очищення баластових вод морських суден. Задана кониепиія трунтується на нанотехнологічних принципах удосконалення очисної споруди баластних вод. Належною перевагою в запропонованій установиі $\epsilon$ необхідні «ключі-підходи», з одного боку, потужного хімічного реагенту, з іншого ж-високотехнологічного конструктивного рішення (вдосконаленого, що включає принщипи електрогідроудару), щзо дає змогу уникнути глибокого «зараження» баластних вод від інвазивних чужорідних видів, зокрема індикаторних мікробів.

Ключові слова: баластні води, загроза морських суден, інвазії, забортна вода, система знезараження та очистки баластних вод, електрогідроудар. 


\section{IMPROVEMENT OF THE SYSTEM OF DECOMPOSITION}

AND CLEANING OF BALLAST WATER

The article deals with the problem of "accumulation-relocation" of alien invasions with constant "transfer" of ballast water on sea-going ships; attention is focused on the basic requirements of the IMO (the International Maritime Organization) Convention (in particular, the more "toughened" requirement D-2). For a given convention (referring to the basic rules and adhering to the basic requirements), a modified and improved schematic concept for the development of a facility for decontamination and cleaning of ballast water of sea vessels is presented by the authors - lectures of the Danube Institute NU "OMA" (Izmail). The given concept is based on nanotechnological principles for improving the ballast water treatment plant. A proper advantage in the proposed installation is the necessary "key approaches", on the one hand, a powerful chemical reagent, on the other hand, a high-tech constructive solution (more advanced, incorporating the principles of electrohydraulic shock) to avoid deep "contamination" of ballast waters from invasive alien species, in particular, also indicator microbes.

Key words: ballast water, safety, threat of sea vessels, invasions, seawater, ballast water treatment and treatment system, electro-hydraulic shock. 